\title{
K. CONVENIO DE 25 DE MARZO DE 1957 SOBRE DETERMINADAS INSTITUCIONES COMUNES A LAS COMUNIDADES EUROPEAS
}

Su Majestad el Rey de los belgas, el Presidente de la República Federal de Alemania, el Presidente de la República Francesa, el Presidente de la Republica Italiana, su Alteza Real la GraN. DuQuesa de LuXemburgo, su Majestad la Reina de los Paf́ses Bajos,

PREOCUPADOS por evitar la multiplicidad de instituciones destinadas a realizar misiones análogas en las Comunidades Europeas por ellos constituidas, HAN DECIDIDO crear, para dichas Comunidades, determinadas instituciones unicas $y$ han designado con tal fin como plenipotenciarios:

Su Majestad el Rey de los belgas:

al señor Paul-Henri Spaak, ministro de Asuntos Exteriores; al barón .J. Ch. Snoy et d'Oppuers, Secretario General del Ministerio de Asuntos Económicos, Presidente de la delegación belga en la Conferencia intergubernamental.

El Presidente de la República Federal de Alemania:

al doctor Konrad Adenauer, Canciller Federal;

al profesor doctor Walter Hallstein, Secretario de Estado de Asuntos Exteriores.

El Presidente de la República Francesa:

al señor Christian Pineau, ministro de Asuntos Exteriores;

al señor Maurice Faure, Secretario de Estado de Asuntos Exteriores.

El Presidente de la República Italiana: 
al señor Antonio Segni, Presidente del Consejo de Ministros;

al profesor Gaetano Martino, ministro de Asuntos Exteriores.

Su Alteza Real la Gran Duquesa de Luxemburgo:

al señor Joseph Bech, Presidente del Gobierno, ministro de Asuntos Exteriores;

al señor Lambert Schaus, Eınbajador, Presidente de la delegación luxemburguesa en la Conferencia intergubernamental.

Su Majestad la Reina de los Países Bajos:

al señor Joseph Luns, ministro de Asuntos Exteriores;

al señor Linthorst Homan, Presidente. de la delegación neerlandesa en la Conferencia intergubernamental.

QUIENES, después de haber intercambiado sus plenos poderes, reconocidos en buena y debida forma,

HAN CONVENIDO las disposiciones siguientes:

\section{SECCION PRIMERA}

\section{LA ASAMBLEA}

Artículo 1. Los poderes y las competencias que el Tratado constitutivo de la Comunidad Económica Europea y el Tratado constitutivo de la Comunidad Europea de la Energía Atómica atribuyen a la Asamblea serán ejercidos, en las condiciones establecidas, respectivamente, en dichos Tratados, por una Asamblea única, compuesta y designada en la forma prevista en el artículo 138 del Tratado constitutivo de la Comunidad Económica Europea y en el articulo 108 del Tratado constitutivo de la Comunidad Europea de la Energia Atómica.

Art. 2. 1. Desde su entrada en funciones, la Asamblea única a que se refiere el artículo anterior sustituirá a la Asamblea Común prevista en el artículo 21 del Tratado constitutivo de la Comunidad Europea del Carbón y del Acero.
La Asamblēa única ejercerá los poderes y competencias que dicho Tratado atribuye a la Asamblea Común, de conformidad con las disposiciones de ese Tratado.

2. A tal fin, en el momento de la entrada en funciones de la Asamblea única mencionada en el artículo anterior, el artículo 21 del Tratado constitutivo de la Comunidad Europea del Carbón y del Acero quedará derogado, siendo sustituido por las disposiciones siguientes:

\section{«Artículo 21}

1. La Asamblea estará compuesta por delegados que los Parlamentos habrán de designar entre sus miembros, de conformidad con el procedimiento que cada Estado miembro establezca.

2. El número de estos delegados será el siguiente:

Alemania: 36.

Bélgica: 14.

Francia: 36.

Italia: 36.

Luxemburgo: 6.

Paises Bajos: 14.

3. La Asamblea elaborará proyectos encaminados a hacer posible su elección por sufragio universal directo, de acuerdo con un procedimiento uniforme en todos los Estados miembros.

El Consejo establecerá por unanimidad las disposiciones pertinentes y recomendará a los Estados miembros su adopción, de conformidad con sus respectivas normas constitucionales.»

\section{SECCION II}

\section{El Tribunal de Justicia}

Art. 3. Las competencias que el Tratado constitutivo de la Comunidad Económica Europea y el Tratado constitutivo de la Comunidad Europea de la Energia Atómica atribuyen al Tribunal de Justicia serán ejercidas, en las condiciones establecidas, respectivamente, en dichos Tratados, por un Tribunal de Justicia único, compuesto y designado 
en la forma prevista en los artículos 165 a 167, ambos inclusive, del Tratado constitutivo de la Comunidad Económica Europea y en los artículos 137 a 139 , ambos inclusive, del Tratado constitutivo de la Comunidad Europea de la Energía Atómica.

Art. 4. 1. Desde su entrada en funciones, el Tribunal de Justicia único mencionado en el artículo anterior sustituirá al Tribunal previsto en el articulo 32 del Tratado constitutivo de la Comunidad Europea del Carbón y del Acero. El Tribunal único ejercerá las competencias que dicho Tratado atribuye al Tribunal, de conformidad con las disposiciones de ese Tratado.

El Presidente del Tribunal de Justicia único a que se refiere el artículo anterior ejercerá las atribuciones que el Tratado constitutivo de la Comunidad Europea del Carbón y del Acero confiere al presidente del Tribunal previsto en dicho Tratado.

2. A tal fin, en el momento de la entrada en funciones del Tribunal de Justicia único mencionado en el artículo anterior,

a) El artículo 32 del Tratado constitutivo de la Comunidad Europea del Carbón y del Acero quedará derogado, siendo sustituido por las disposiciones siguientes:

\section{(Artículo 32}

El Tribunal estará compuesto por siete jueces.

El Tribunal se reunirá en sesión plenaria. No obstante, podrá constituir Salas compuestas por tres o cinco jueces, con objeto de proceder a determinadas diligencias de instrucción o de conocer en determinadas categorias de asuntos, en las condiciones previstas en un reglamento adoptado al respecto.

En cualquier caso, el Tribunal se reunirá en sesión plenaria para pronunciarse sobre los asuntos promovidos por un Estado miembro o una institución de la Comunidad, así como sobre las cuestiones prejudiciales que le sean planteadas en virtud del artículo 41 .
Si el Tribunal lo solicitare, el Consejo, por unanimidad, podrá aumentar el número de jueces y realizar las adaptaciones necesarias en los párrafos segundo y tercero del presente artículo, así como en el párrafo segundo del articulo 32 ter.»

\section{«Artículo 32 bis}

El Tribunal está asistido por dos abogados generales.

$\mathrm{La}$ función del abogado general consistirá en presentar públicamente, con toda imparcialidad e independencia, conclusiones motivadas sobre los asuntos promovidos ante el Tribunal, a fin de asistirle en el cumplimiento de su misión, tal como queda definida en el artículo 31 .

Si el Tribunal lo solicitare, el Consejo, por unanimidad, podrá aumentar el número de abogados generales y realizar las adaptaciones necesarias en el párrafo tercero del artículo 32 ter.y

\section{«Art. 32 ter}

Los jueces y los abogados generales, elegidos entre personalidades que ofrezcan absolutas garantías de independencia y que reúnan las condiciones requeridas para el ejercicio, en sus respectivos paises, de las más altas funciones jurisdiccionales o que sean jurisconsultos de reconocida competencia, serán designados de común acuerdo por los Gobiernos de los Estados miembros por un periodo de seis años.

Cada tres años tendrá lugar una renovación parcial de los jueces. Dicha renovación afectará alternativamente a tres y cuatro jueces. Los tres jueces cuya designación esté sujeta a renovación al final del primer periodo de tres años serán designados por sorteo.

Cada tres años tendrá lugar una renovación parcial de los abogados generales. El abogado general cuya designación esté sujeta a renovación al final del primer período de tres años será designado por sorteo.

Los jueces y los abogados generales salientes podrán ser nuevamente designados. 
Los jueces elegirán de entre ellos al presidente del Tribunal por un periodo de tres años. Su mandato será renovable.»

\section{«Art. 32 quater}

El Tribunal nombrará a su secretario y establecerá el estatuto de éste.r;

b) las disposiciones del Protocolo sobre el Estatuto del Tribunal de Justicia anejo al Tratado constitutivo de la Comunidad Europea del Carbón y del Acero quedarán derogadas en tanto en cuanto sean contrarias a los artículos 32 a 32 quater, ambos inclusive, de dicho Tratado.

\section{SECCION III}

\section{El Comite Económico Social}

Art. 5. 1. Las funciones que el Tratado constitutivo de la Comunidad Económica Europea y el Tratado constitutivo de la Comunidad Europea de la Energía Atómica asignan al Comité Económico y Social serán ejercidas, en las condiciones establecidas, respectivamente, en dichos Tratados, por un Comité Económico y Social único, compuesto y designado en la forma prevista en el artículo 194 del Tratado constitutivo de la Comunidad Económica Europea y en el artículo 166 del Tratado constitutivo de la Comunidad Europea de la Energia Atómica.

2. El Comité Económico y Social único a que se alude en el párrafo anterior contará con una sección especializada, y podrá comprender subcomités competentes en las materias o cuestiones propias del Tratado constitutivo de la Comunidad Europea de la Energía Atómica.

3. Las disposiciones de los artículos 193 y 197 del Tratado constitutivo de la Comunidad Económica Europea serán aplicables al Comité Económico y Social único mencionado en el apartado 1.

\section{SECCION IV}

FinANCIACIÓN DE ESTAS INSTITUCIONES

Art. 6. Los gastos de funcionamiento de la Asamblea única, del Tribu- nal de Justicia único y del Comité Económico y Social único se repartirán, por partes iguales, entre las Comunidades interesadas.

Las autoridades competentes de cada Comunidad determinarán de común acuerdo las modalidades de aplicación del presente artículo.

\section{DisPosiciones FINALES}

Art. 7. El presente Convenio será ratificado por las Altas Partes Contratantes de conformidad con sus respectivas normas constitucionales. Los instrumentos de ratificación serán depositados ante el Gobierno de la Republica Italiana.

Ël presente Convenio entrará en vigor en la misma fecha de entrada en vigor del Tratado constitutivo de la Comunidad Económica Europea y del Tratado constitutivo de la Comunidad Europea de la Energía Atómica.

Art. 8. El presente Convenio, redactado en un ejemplar único, en lengua alemana, lengua francesa, lengua Italiana y lengua neerlandesa, cuyos cuatro textos son igualmente auténticos, será depositado en los archivos del Gobierno de la República Italiana, que remitirá una copia certificada conforme a cada uno de los Gobiernos de los restantes Estados signatarios.

EN FE DE LA CUAL, los plenipotenciarios abajo firmantes suscriben el presente Convenio.

Hecho en Roma, el 25 de marzo de 1957.

P. H. Spaak.

Adenauer.

Pineau.

Antonio Segni.

Bech.

J. Luns.

J. Ch. Snoy et d'Oppuers.

Hallstein.

M. Faure.

Gaetano Martino.

Lambert Schaus.

J. Linthorst Homan. 